\title{
Value analysis committees: Not just another committee to get out of
}

\author{
David D. Yuh, MD, FACS, FACC
}

From the Department of Surgery, Stamford Hospital, Stamford, Conn.

Disclosures: Author has nothing to disclose with regard to commercial support.

Received for publication Oct 31, 2017; accepted for publication Nov 10, 2017; available ahead of print Dec 6, 2017

Address for reprints: David D. Yuh, MD, FACS, FACC, One Hospital Plaza, PO Box 9317, Stamford, CT 06904 (E-mail: DYuh@stamhealth.org).

J Thorac Cardiovasc Surg 2018;155:686-7

0022-5223/\$36.00

Copyright (C) 2017 by The American Association for Thoracic Surgery

https://doi.org/10.1016/j.jtcvs.2017.11.033

Value analysis committees (VACs) are viewed by many surgeons as formidable, exasperating barriers to their efforts in acquiring new technologies to improve patient outcomes. The opinion piece in this issue of the Journal by Engelman and colleagues ${ }^{1}$ cogently outlines the shortcomings of VACs. From one perspective, the analytic focus of most if not all VACs is on controlling shortterm costs and optimizing early returns on investment in a new product, rather than on assessing its impact on the total cost of care, which is far more relevant to current and anticipated bundled reimbursement models. Furthermore, the variegated composition, unpredictable thought-processes, lack of a clear definition of a product's "value," and siloed budgets associated with current VACs severely limit their ability to unlock more substantial cost savings from institution- or system-wide standardization and supply chain strategies. We should acknowledge, however, that surgeons have been known to request expensive new products primarily driven by efforts to differentiate themselves from competitor colleagues in tight markets, justifying them with case volume, clinical outcome, and cost savings projections that are based on little more than wishful thinking or industry-fueled hype. The ongoing reinvention of cardiac surgery largely through the development of often costly new device technologies (eg, minimally invasive instrumentation, circulatory support devices, and structural heart interventions) has rendered the VAC process particularly frustrating for cardiac surgeons, because these committees and surgeons often view a new product through entirely different prisms.

Having defined the problem, Engelman and colleagues ${ }^{1}$ provide a blueprint to bring VACs more in line with contemporary assessments of a given product's true value. Many features of this blueprint are intuitive and consistent with contemporary fiscal management principles used by successful businesses today, which prompts the question: Why are there no real-world

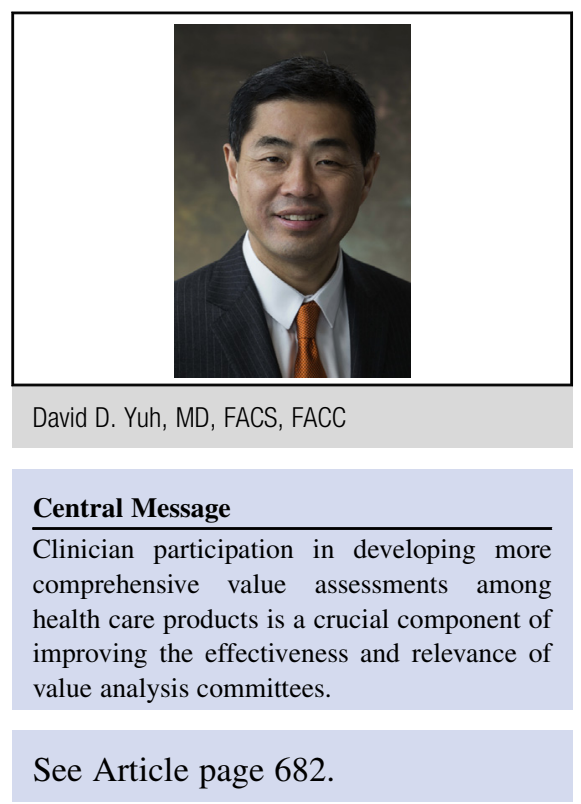

examples of the "evolved" hospital VACs that Engelman and colleagues ${ }^{1}$ advocate? Part of the answer lies in the reality that ascertaining and optimizing value-based outcomes afforded by new products requires substantial time, resources, and, above all, interest, from all key stakeholders. Expertise in assessing value-based outcomes continues to be ceded to administrators by clinicians, perhaps fatalistically as "somebody else's problem." When I performed a PubMed search to familiarize myself with the medical community's most recent perspectives and efforts pertaining to refining the quantification of a biomedical product's value by VACs, it yielded no relevant citations...none. Hospitals differ from most businesses in that they just do not manufacture and sell widgets or provide a well-circumscribed set of services, and they therefore struggle with meaningful quantifications of a product's value. The measure of health care value is a dynamic, multidimensional process, and it always will be as long as our understanding and treatment of disease processes across a myriad of medical and surgical subspecialties advance. Until and unless (1) physicians, surgeons, and their respective societies more actively engage with their regulatory and administrative counterparts in more comprehensive definitions of value among health care products and (2) these discussions become part of the medical vernacular, the (dys)function 
of VACs will be perpetually subject to the determinations of well-meaning committee members who are nevertheless ill-equipped to make effective determinations.

\section{Reference}

1. Engelman DT, Boyle EM Jr, Benjamin EM. Addressing the imperative to evolve the hospital new product value analysis process. J Thorac Cardiovasc Surg. 2018; 155:682-5. 